\title{
Remote Sensing as Pest Forecasting Model in Agriculture
}

\author{
D. Sudha Rani ${ }^{1 *}$, M.N. Venkatesh ${ }^{2}$, Ch. Naga Satya Sri ${ }^{2}$ and K. Anand Kumar ${ }^{2}$ \\ ${ }^{1}$ Scientist (Entomology), Agricultural Research Station, Garikapadu, Krishna dt, India \\ ${ }^{2}$ Agricultural Polytechnic, Garikapadu, Krishna dt, India
}

*Corresponding author

\begin{tabular}{|l|}
\hline K e y w o r d s \\
Remote sensing, \\
$\begin{array}{l}\text { Forecasting } \\
\text { model, Pests }\end{array}$ \\
\hline Article Info \\
\hline $\begin{array}{l}\text { Accepted: } \\
\text { 24 February } 2018 \\
\text { Available Online: } \\
\text { 10 March } 2018\end{array}$
\end{tabular}

\section{Keywords}

Remote sensing,

Forecasting

model, Pests

\section{A B S T R A C T}

Agriculture plays a dominant role in the growth of Indian economy contributing nearly 28 per cent towards Gross Domestic Product (GDP). Insect pests (14 per cent), diseases and weeds inflict enormous losses to the potential agricultural production. The yield losses due to pest population can be suppressed to be greater extent if their incidence is known well in advance so that timely adoption of remedial measures is possible. This led to a concept of 'forecasting' which is an important component of the IPM strategy. Forecasting methods are based on the models that utilize data on weather parameters, farmer's eye estimates, agrometerological conditions, remote sense crop reflectance observations etc. either separately or in an integrated manner. The visual detection of plant responses to biotic stresses with acceptable levels of accuracy, precision and speed is difficult. These responses affect the amount and quality of electromagnetic radiation reflected from crop canopies. Hence, remote sensing is the technique involving instruments that measure and record the changes in electromagnetic radiation and provides better means of objectively quantifying biotic stresses in comparison to visual assessment methods. In this review article, briefed the concept, principles and types of remote sensing with some case studies to augment the acquaintance on the concept of "Remote Sensing" as pest forecasting model.

\section{Introduction}

Technologies based on plant protection research for major pests are of utmost important to attain sustainability in agriculture (Pratap et al., 2000). The yield losses due to pest population can be suppressed to be greater extent if their incidence/occurrence is known well in advance so that timely adoption of remedial measures is possible. This led to a concept of 'forecasting', a prediction or estimate of future trend which involves all the activities in ascertaining and notifying the growers of community that conditions are sufficiently favourable for certain insect pests, that application of control measures will result in economic gain or on the other hand and just as important that the amount expected is unlikely to be enough to justify the expenditure of time, energy and money for 
control (Miller and O'Brien, 1952). Forecast for pests is an important component of the IPM strategy. Early warnings and forecasts based on biophysical methods provide lead time for managing impending pest attacks and can thus minimize crop loss, optimize pest control and reduce the cost of cultivation.

Prevailing and anticipated weather information can help in crop planning and scheduling spray' and farm operations to maximize crop yields and returns. It provides advance information for outbreak of pests/diseases attack so that effective plant' protection measures can be implemented before the actual onset of the damage.

Remote sensing is the science of deriving information about an object or phenomena through analysis of data acquired by a device that is not in contact with the object or phenomena under investigation. Remote sensing is the examination or the gathering of information about a place from a distance. Such examination can occur with devices (e.g. cameras) based on the ground, and/or sensors or cameras based on ships, aircraft, satellites or other spacecraft (Prabhakar et al., 2012).

The visual detection of plant responses to biotic stresses with acceptable levels of accuracy, precision and speed is difficult. These responses affect the amount and quality of electromagnetic radiation reflected from crop canopies. Hence, remote sensing is the technique involving instruments that measure and record the changes in electromagnetic radiation and provides better means of objectively quantifying biotic stresses in comparison to visual assessment methods besides repeated used to collect sample measurements non-destructively and noninvasively (Yang et al., 2004).

Remote sensing techniques are useful in detecting crop stresses like nutrient deficiency, pest infestation, disease development and to monitor drought. It improves spatial and temporal resolution compared with traditional methods for pest monitoring (Datta et al., 2008).

\section{Principle of remote sensing}

Every object reflects/scatters a portion of electromagnetic energy incident on it depending on its physical properties. In addition, objects emit radiation depending on their temperature and emissivity. The reflectance/emittance of any object at different wavelengths follow a pattern which is characteristic of that object, known as spectral signature (Plate 1).

In general the healthy plants give a higher reflectance in the near infrared region and a lower one in the visible region and opposite is the situation with the infected plants (Plate 2). The plant stress usually results in an increase in visible reflectance due to decrease in chlorophyll and resulting decrease in absorption of visible light.

\section{Types of remote sensing platforms}

Three types of remote sensing platforms are basically involved to predict the plant biotic stresses.

\section{Types of spectral scanner scan}

Depending on the band width the number of bands and contiguous nature of recording spectral scanner scan be of two types (Fig. 1).

\section{Kinds of resolution}

The data the RS sensors capture is often characterized by four kinds of resolutions

Spatial (the smallest resolvable unit on the ground, also called the pixel) 
Spectral (how sensitive is the sampled spectra)

Temporal (how often the data can be captured) and

Radiometric (the ability to discriminate very slight differences in reflected or emitted energy (Kelly and Guo, 2007)

\section{Concept of spectral vegetation index}

A vegetation index (VI) can be defined as a dimensionless, radiation based measurement computed from the spectral combination of remotely sensed data.

These VIs are quantitatively and functionally related with canopy parameters such as the leaf area index (LAI), aboveground biomass, chlorophyll and other leaf pigment content and vegetation fraction and have potential applications in agriculture in general and for monitoring pests and diseases in particular (Pena and Altman 2009).

The normalized difference vegetation index (NDVI) is the most commonly used ratio based vegetative indexes which differs from plant to plant and also within the same plant depending on the varieties, DAS, fertilizer application etc (Fig. 2).

NDVI: (NIR-RED) / (NIR+RED)

NIR: Near Infra Red spectrum

RED: Red spectrum of visible light energy

The higher the NDVI value, the healthier the green vegetation

\section{Applications of remote sensing in pest management}

Photography and videography from aircraft and from the ground

Satellite-borne multispectral scanning (MSS)
Thermal imaging

Ground based and airborne radar methods (Riley, 1989)

\section{Remote Sensing (RS) techniques in pest management}

The observation of insect themselves

The detection of the effects that insects produce (Symptoms)

The monitoring of environmental factors likely to influence insect occurrence/ abundance, potential damage

\section{The pest damage can be predicted with}

Spectral indices based on leaf pigments

Optical and video imaging in near infrared and microwave regions

Multi Spectral Remote Sensing (MRS)

Areas identification with help of portable GPS equipment

\section{Studies on incidence of insects through RS}

The effect of Russian Wheat aphid and green bugs on leaf reflectance by wheat seedlings is due lower chlorophyll concentrations and displayed wavelengths of 500-525, 625-635 and 685-695 nm (Riedell and Blackmer, 1999).

It is possible to detect the stress caused by the $\mathrm{BPH}$ in rice using remote sensing. 1813-1836 $\mathrm{nm}$ may be most sensitive to BPHs infestation at canopy measurement level (Zhou et al., 2010).

Color and colour-infrared aerial photography with conventional camera have been used 
effectively to delineate damage caused by a number of serious pests like hemlock looper and Bark beetles (Plate 6).

The stress caused by aphid species is detected by mapping of Mississippi river delta revealed the most probable areas where insects might attack the wheat crop is predicted through remote sensing (Yang et al., 2009) (Plate 7).

\section{Studies on distribution of insects through RS}

Aerial photography was used to study distribution of host plants of tropical fruit flies in Hawaii, El Salvador and Mexico (Hart et al., 1978).

The map areas of milkweed (Asclepias spp.), a major host of monarch butterfly (Danaus plexippus) (Malcom et al., 1993).

SPOT and Landsat 5 high resolution imagery have been used to identify rice production areas in northern Luzon, the Philippines that could act as host for brown planthopper, Nilaparvata lugens.

\section{Studies on distribution of insects through RS}

The migration of grasshoppers in the Niger flood plain in West Africa and in the SahelI. In both cases evidence was found for flights over $100 \mathrm{~km}$ per night.

With $10 \mathrm{~cm}$ radar, detected concentrations of airborne aphids upto $1200 \mathrm{~m}$ above ground (Riley and Reynolds, 1979).

\section{Remote sensing of insect movements through radars}

Radars transmit from their antennas a narrow, conical beam of short (typically 0.1 to 0.05 us) pulses of electromagnetic waves (Plate 8).
Any object illuminated by a pulse reflects or scatters some of the pulse energy and a part of the scattered energy (the echo) is returned in the direction of the radar.

This is detected and amplified and the presence of the target is displayed in a special device

Radar observations of $S$. exempta, showed that this species is an obligate wind borne migrant (Pedgley et al., 1993).

Joyce (1976) emphasized that only a small fraction $(<10 \%)$ of $H$. armigera moths in flight climbed beyond their boundary layer.

Northerly movements of corn earworm moths, $H$. zea and tobacco budworm moths, $H$. virescens from Mexico to the United States (Wolf et al., 1995).

Hence, Remote sensing technology can provide necessary data for assessing pest incidence/occurrence/potential

damage/outbreak threats and post-outbreak damage.

This technology is a means to rapidly collect information on vegetation and earth surface conditions for relatively large geographic areas.

\section{Geographic Information System (GIS)}

GIS is a system capable of assembling, storing, manipulating and displaying the geographically referred information. It consists of spatial information of coordinates; data base of attributes and someway link to both.

GIS abstracts world into layers of spatial and attribute data i.e., one layer for one feature or theme and different themes are brought together using layers (Plate 9). 
Plate.1 The reflections of Electromagnetic energy

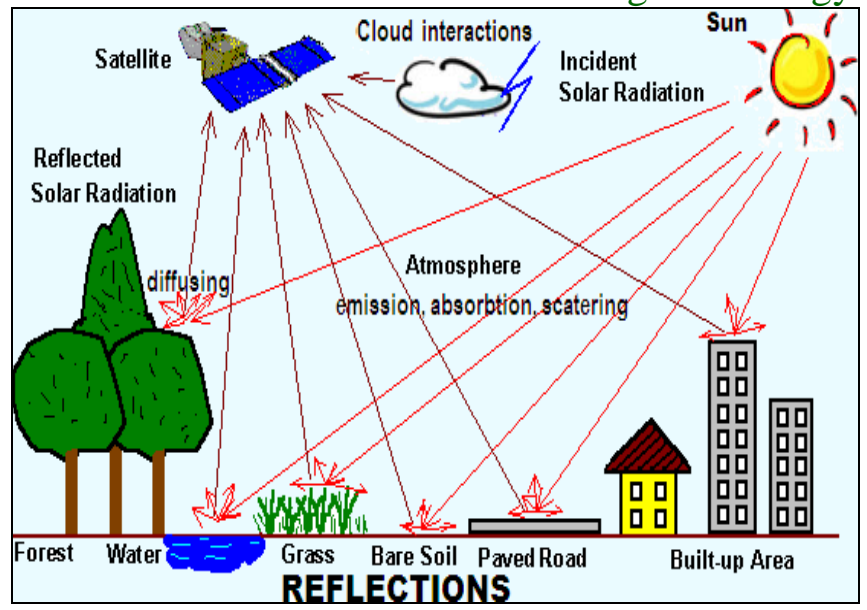

Plate.2 Typical spectral curve of healthy plant

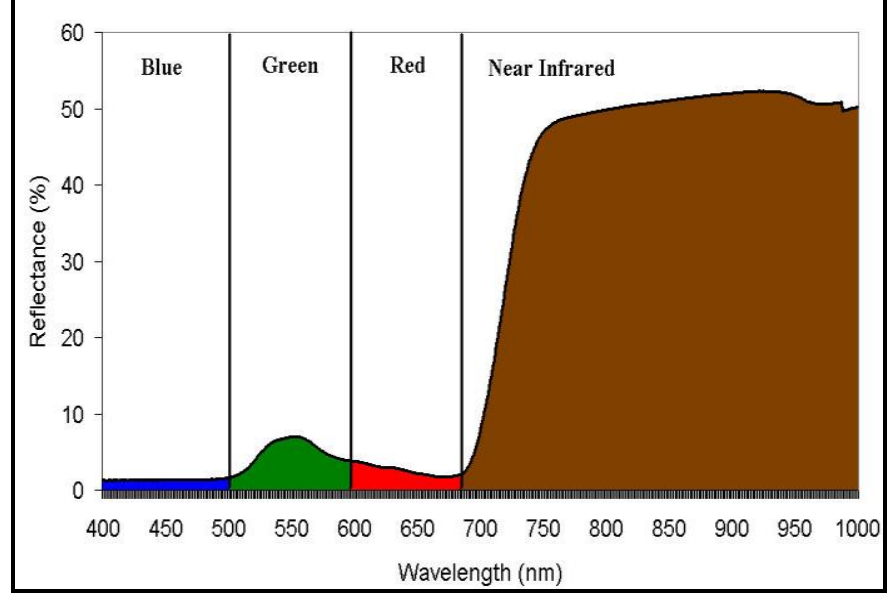

Plate.3 Ground based remote sensing

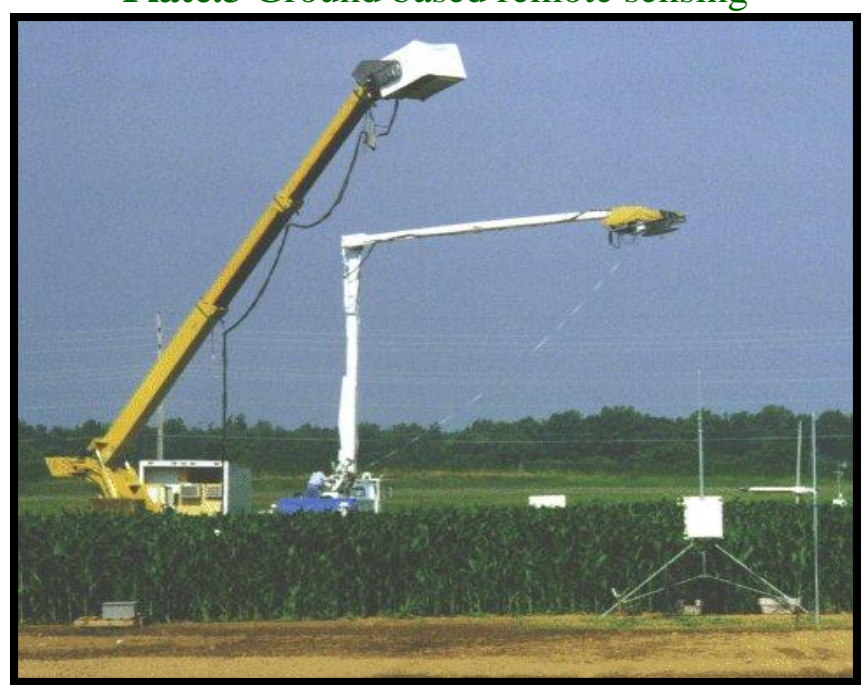

Plate.4 Satellite based remote sensing

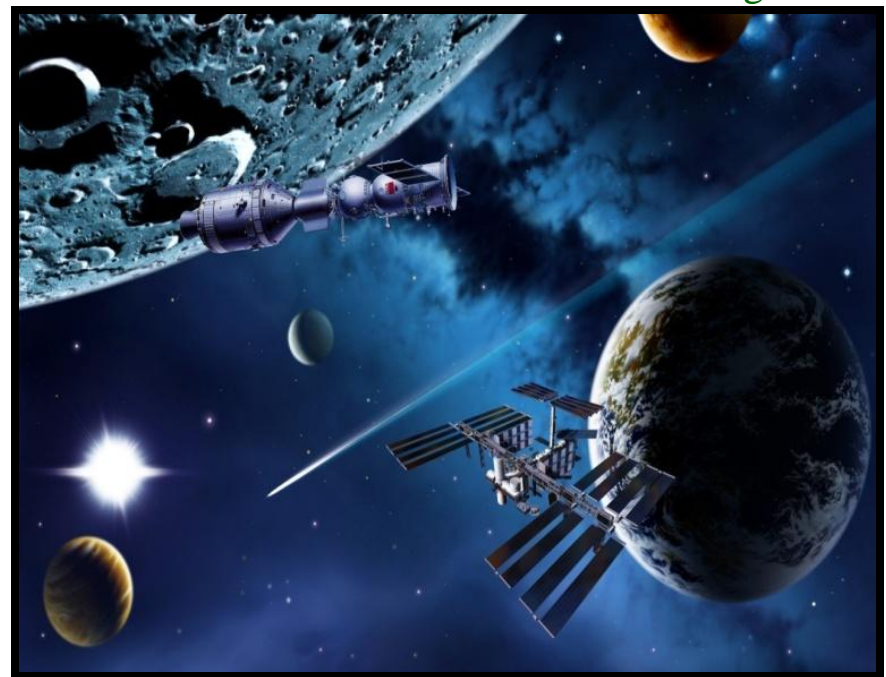

Plate.5 Aircraft remote sensing

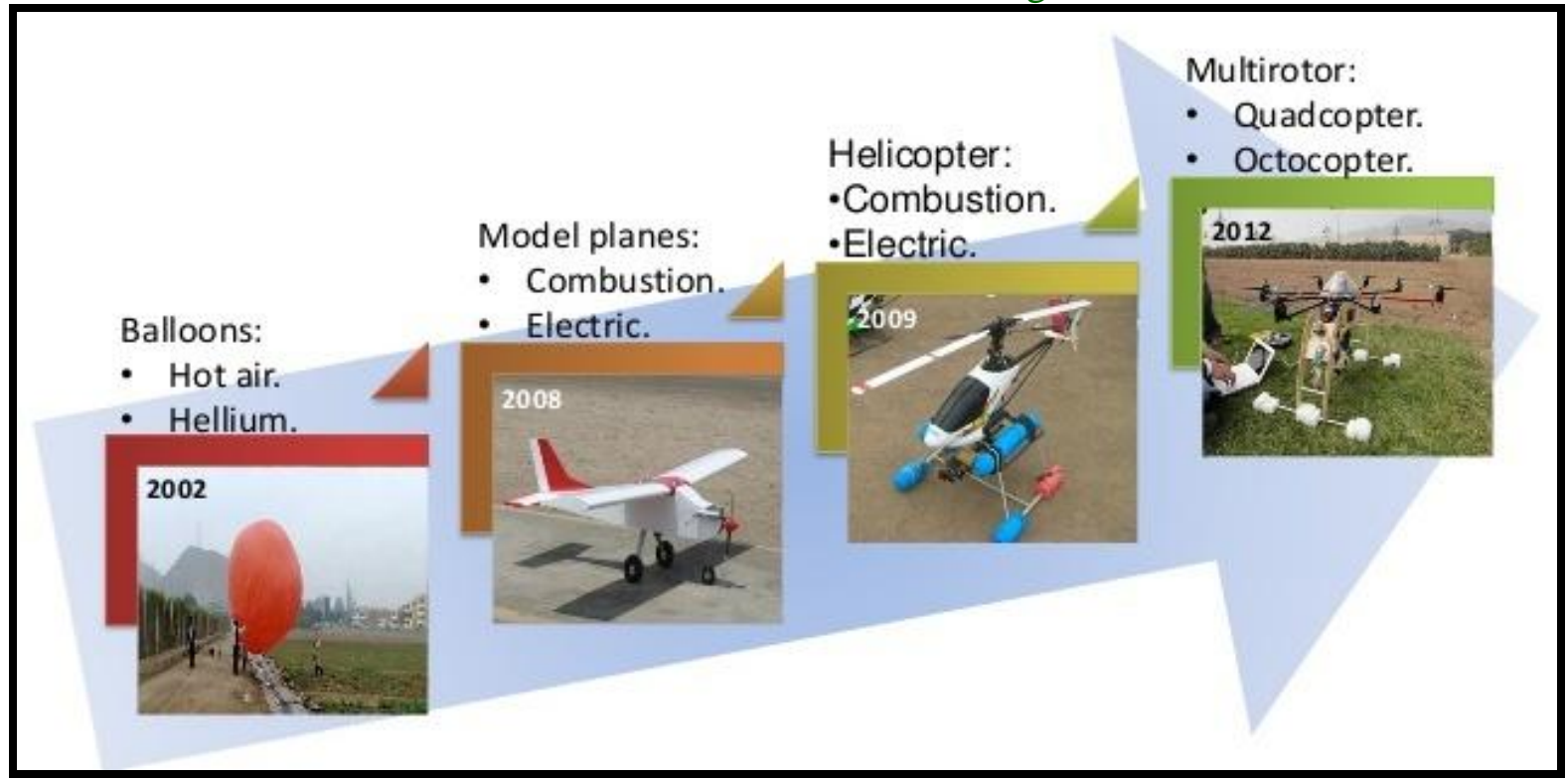


Fig.1 Spectral scanner

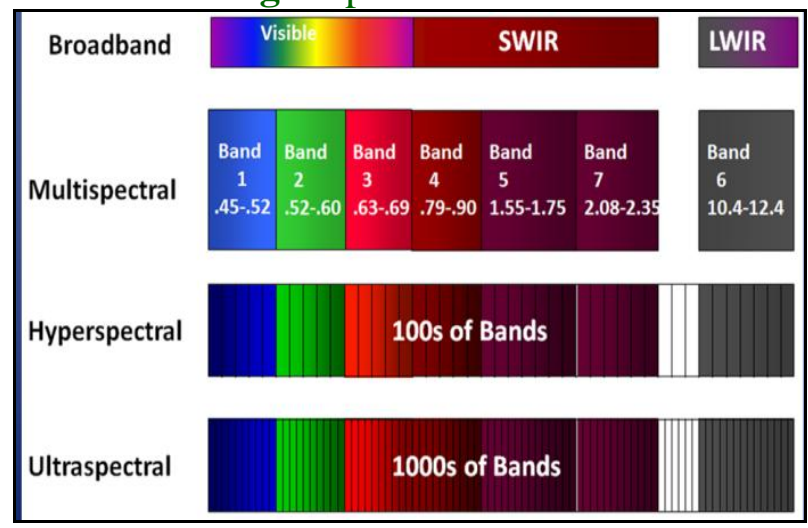

Fig.2 Variations in spectral reflectance

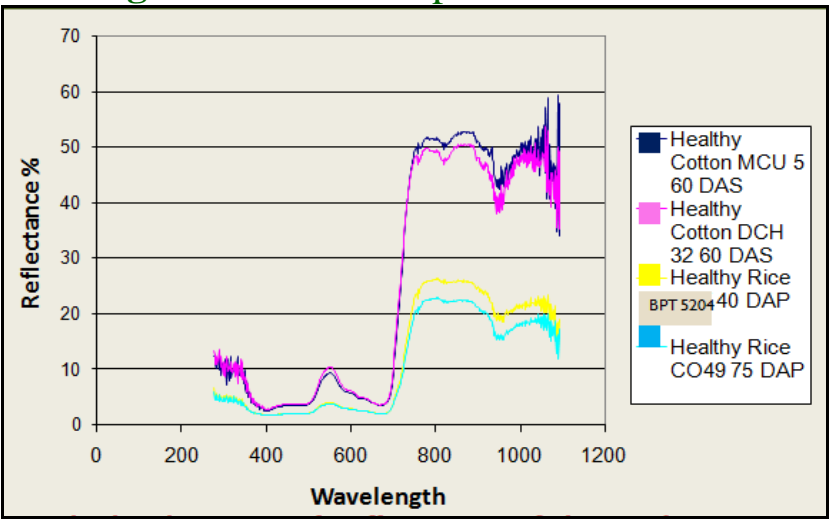

Plate.6 Aerial photograph through remote sensing

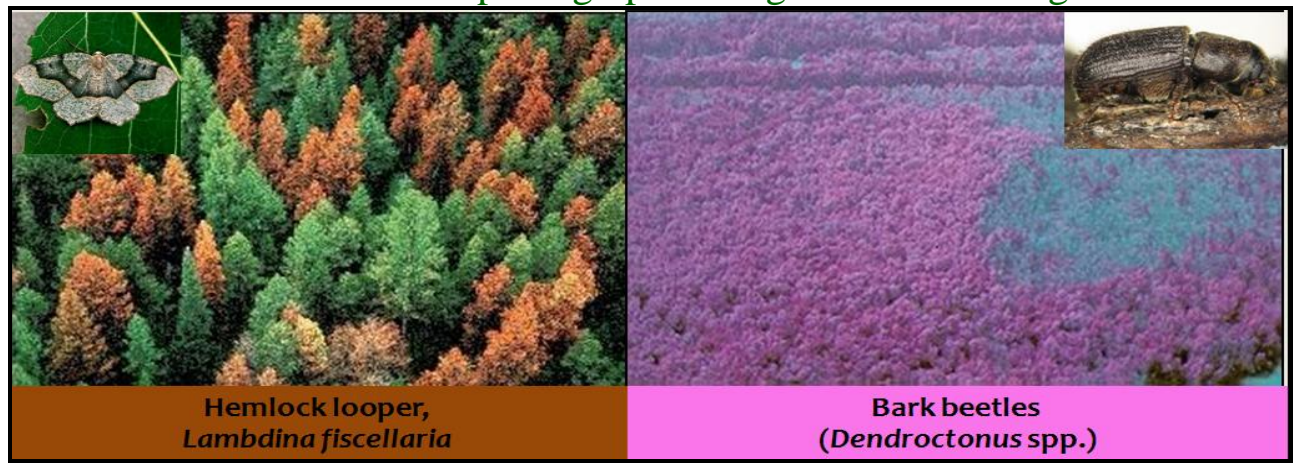

Plate.7 Mapping of Mississippi River delta-most probable areas of aphid attack in wheat

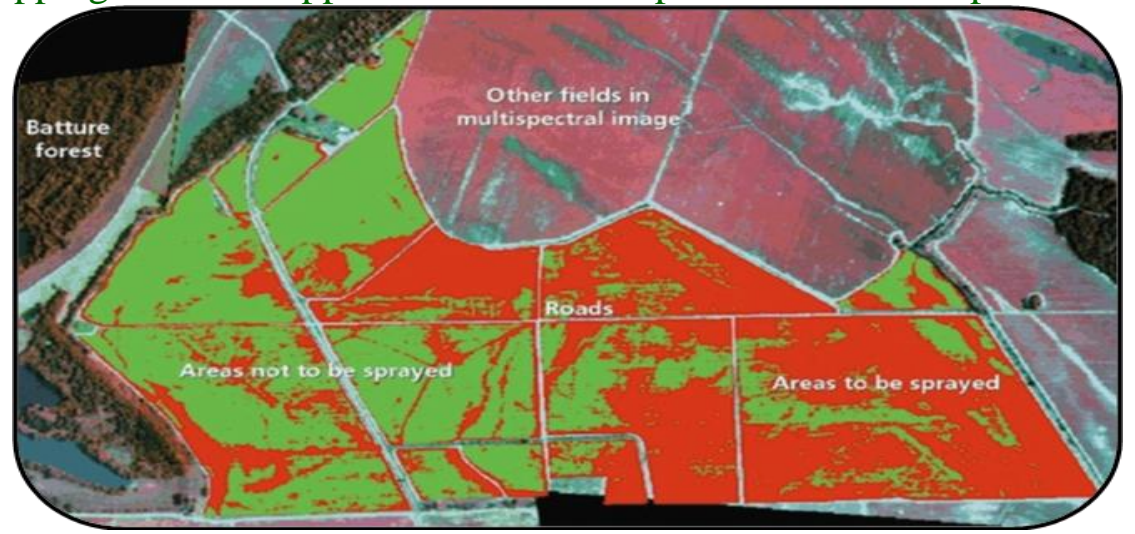

Plate.8 Radar in remote sensing
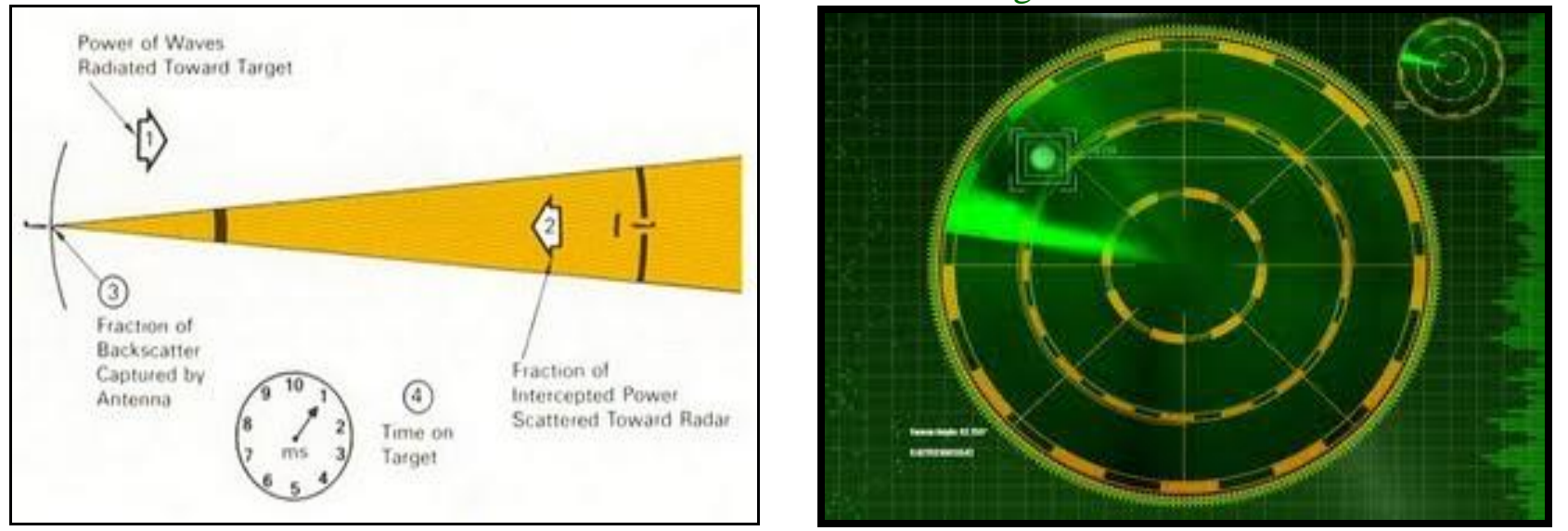
Plate.9 The structure of GIS

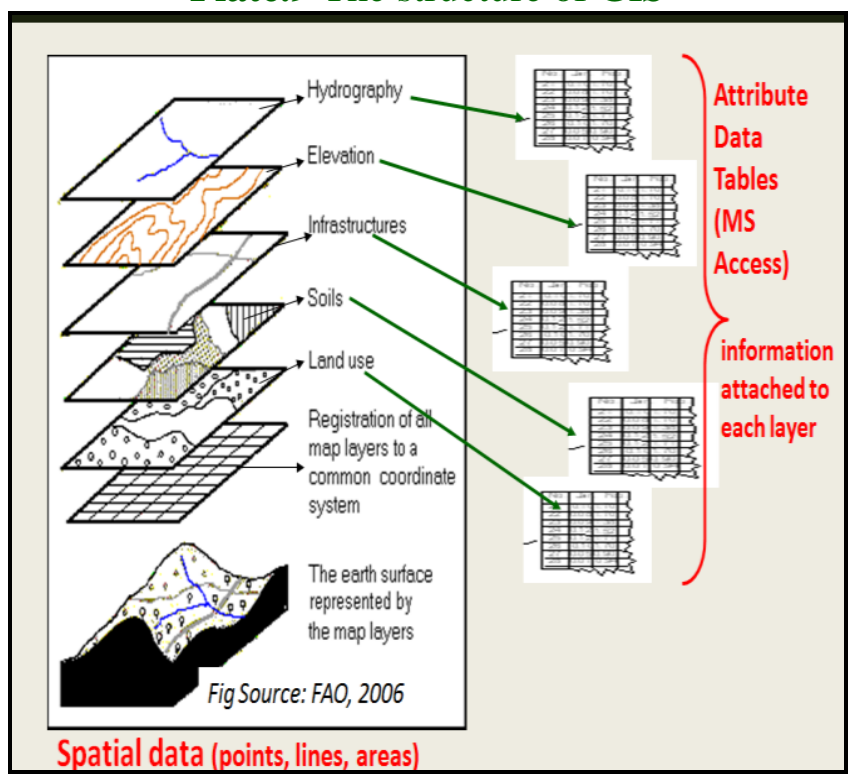

Plate.10 Desert locust forecasting

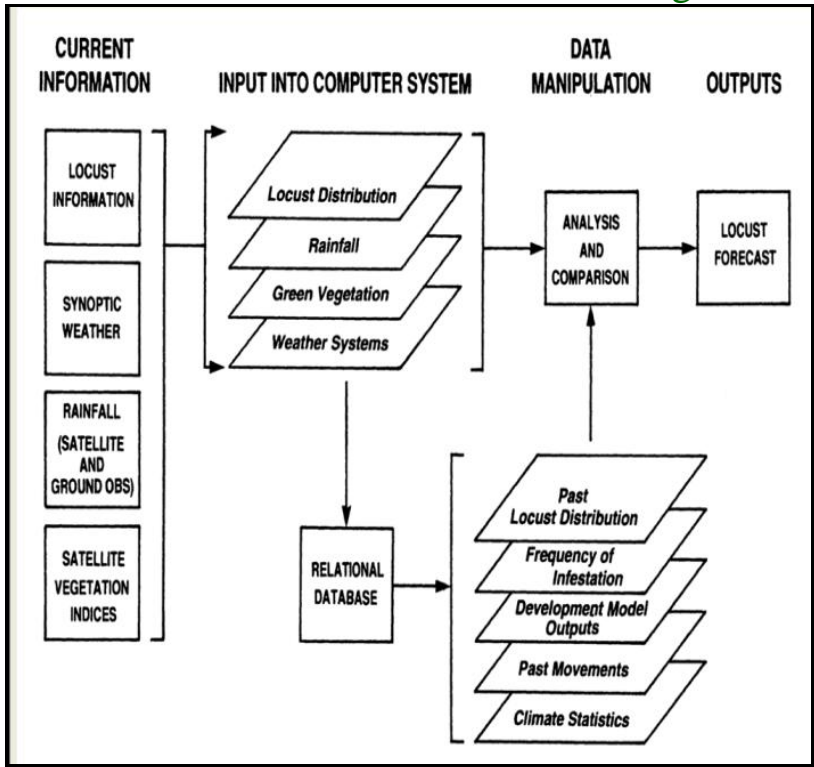

Plate.11 SPOT-VGT and MODIS imagery to monitor Locust swarms
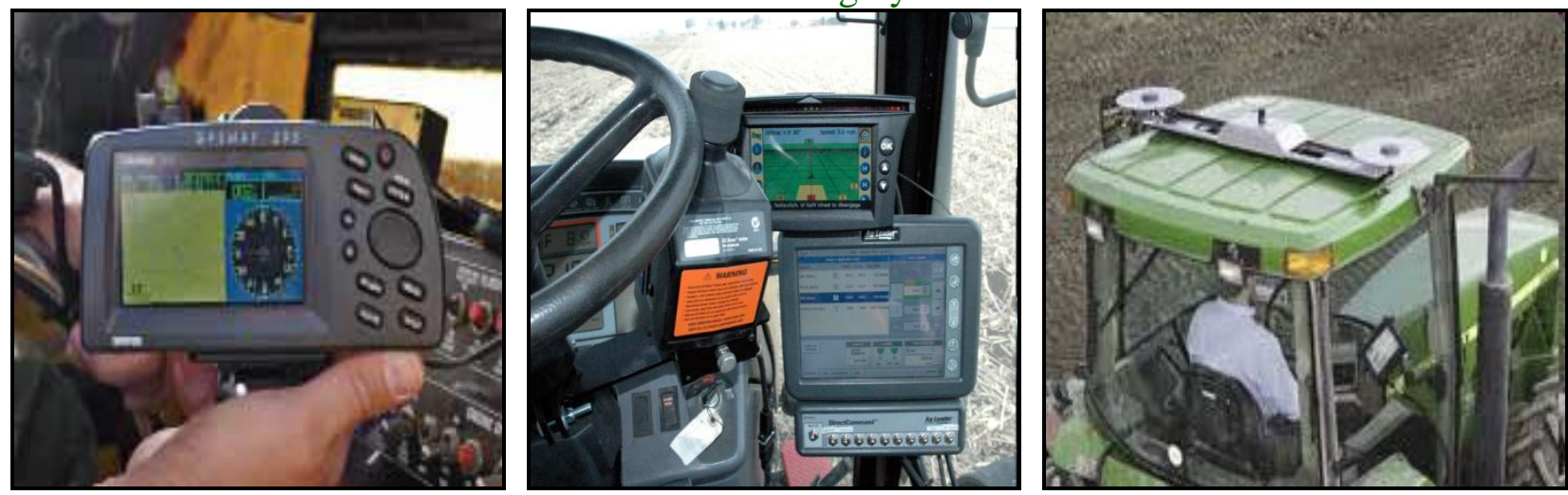

Table.1 Criteria for successful forecast system

\begin{tabular}{|l|l|l|l|}
\hline a. & Reliability & : & Use of sound biological and environmental data \\
\hline b & Simplicity & $\mathbf{E}$ & $\begin{array}{l}\text { The simpler the system, the more likely it will be applied and used } \\
\text { by producers }\end{array}$ \\
\hline c. & Importance & The insect pest is of economic importance to the crop \\
\hline d. & Usefulness & $\begin{array}{l}\text { The forecasting model should be applied when the insect can be } \\
\text { detected reliably }\end{array}$ \\
\hline e. & $\begin{array}{l}\text { Multipurpose } \\
\text { applicability }\end{array}$ & $\begin{array}{l}\text { Monitoring and decision-making tools for several diseases and } \\
\text { pests should be available }\end{array}$ \\
\hline f. & $\begin{array}{l}\text { Cost effectiveness } \\
\text { : }\end{array}$ & $\begin{array}{l}\text { Forecasting system should be cost affordable relative to available } \\
\text { insect pest management tactic ssuccessful forecast }\end{array}$ \\
\hline
\end{tabular}


Table.2 Types of Remote sensing Platforms

\begin{tabular}{|c|l|l|l|}
\hline 1 & $\begin{array}{l}\text { Ground based } \\
\text { (Field based) }\end{array}$ & $\begin{array}{l}\text { Field based platform, such as handheld spectro radiometer, is } \\
\text { typically used for ground studies (Plate 3). }\end{array}$ \\
\hline 2 & $\begin{array}{l}\text { Mlounted on } \\
\text { aircrafit (Airborne) }\end{array}$ & $\begin{array}{l}\text { Air borne remote sensing is flexible and able to achieve different } \\
\text { spatial resolutions with different flight altitudes (Plate 4). }\end{array}$ \\
\hline $\mathbf{3}$ & $\begin{array}{l}\text { Senerally used for large area study but often many times it cannot } \\
\text { meet the requirements of spatial resolutions in applications (Plate 5). }\end{array}$
\end{tabular}

Table.3 Types of Spectral Scanner Scan

\begin{tabular}{|l|l|l|l|l|l|}
\hline 1. & $\begin{array}{l}\text { Multispectral or } \\
\text { Broad band }\end{array}$ & $\begin{array}{l}\text { Sense several wavebands in a wider range of discrete } \\
\text { wavelengths. Multispectral systems measure energy in specific, } \\
\text { strategically restricted portions of the electromagnetic } \\
\text { spectrum }\end{array}$ \\
\hline 2. Hyperspectral or & $: \begin{array}{l}\text { Scanners provide the opportunity to sense many very narrow } \\
\text { wavebands over a wide. Hyperspectral systems measure several } \\
\text { consecutive wavebands across a specified region of the } \\
\text { electromagnetic spectrum }\end{array}$ \\
\hline
\end{tabular}

\section{SWARMS Schistocerca Warning Management System}

\begin{tabular}{|l}
$\begin{array}{l}\text { A work station-based GIS to support the administration, mapping and analysis of data } \\
\text { for operational forecasting of Desert Locusts across the whole distribution area at } \\
\text { FAO's centralized Desert Locust Information Service in Rome. }\end{array}$ \\
\hline Reconnaissance And Management System for the Environment of Schistocerca \\
\hline $\begin{array}{l}\text { A PC-based system designed to assist national locust units in storing, analyzing and } \\
\text { disseminating Desert Locust and related environmental information derived mainly } \\
\text { from their own data capturing network. (Healey et al., 1996) }\end{array}$
\end{tabular}

\section{Application of GIS in pest management}

Characterization of habitat susceptibility to outbreaks and compilation of census data

Shepherd et al., (1988) digitized historical maps of defoliation caused by the Douglas-fir tussock moth in British Columbia from 192486.

This outbreak frequency map was then overlaid with forest type and bio geoclimatic maps to determine how forest type and climate were related to outbreak frequency.

\section{Insect census data and GIS}

Liebhold (1996) stated that the use of a GIS to interpolate gypsy moth trap counts and egg mass densities in an IPM demonstration program aids in insect census. The map compilations of these data are useful for planning suppression activities. GIS based Desert Locust Management Systems (Plate 9 \& 10)

\section{Locust monitoring at FAO}

Desert Locust Information Service (DLIS) uses rainfall estimates derived from 
METEOSAT, mainly infrared and visible channels, to understand better the spatial and quantitative distribution of rainfall in the Desert Locust breeding areas. SPOT-VGT and MODIS imagery is made available every 10 and 16 days respectively to locust-affected countries (Plate 10). These products are used to help guide national survey teams to potential areas of green vegetation where Desert Locust may be present.

In view of the above, it is concluded that various expert systems for forewarning pests have the capability to transfer location specific technology and advice to the farmers efficiently and effectively. Direct dissemination of expert knowledge to agricultural producers through computer programs will increase product quality as well as the profit margin.

\section{References}

Datta, R., Joshi, D. Li. J., and Wang, J. Z. 2008. Image retrieval: Ideas, influences and trends of the new age. $A C M$ Computing Surveys. 40:1-60.

Hart, W.G and Meyers, V.I. 1978. Infrared aerial color photography for detection of populations of brown soft scale in citrus groves. Journal of Economic Entomology. 61(3): 617-624.

Healey, R., Robertson, S.G., Magor, J.I and Cressman, L K.1996.A GIS Desert locust forecasting and monitoring. Geographical Information Systems.10 (1): 117-136

Joyce, R.J.V. 1976. Insect flight in relation to problems of pest control. in Insect flight (ed. R.C. Rainey). Symposia of the Royal Entomological Society of London 7. Oxford, UK: Blackwell.pp135-155.

Kelly, M and Guo, Q. 2007. Integrated agricultural pest management through remote sensing and spatial analysis. In: Ciancio A, Mukerji KG (eds) General concepts in integrated pest and disease management. Springer, New York. pp 191-207.

Liebhold, A., Luzader, E., Reardon, R., Bullard, A., Roberts, A., Ravlin, F.W., DeLost, S and Spears, B. 1996. Use of a geographic information system to evaluate regional treatment effects in a gypsy moth (Lepidoptera: Lymantriidae) management program. Journal of Economic Entomology. 89: 1192-1203.

Malcolm, S.B., Cockrell, B.J and Brower, L.P.1993. Spring recolonization of eastern North America by the monarch butterfly: successive brood or single sweep migration? In S.B. Malcolm and M.P. Zalucki, editors. Biology and Conservation of the Monarch Butterfly 253-267. Natural History Museum of Los Angeles Country

Miller, P.R and O'Brien, M.J. 1952. Plant disease forecasting. The Botanical review. 18: 547-601.

Pedgley, D.E. 1993. Managing migratory insect pests-a review. International Journal of Pest Management. 39: 3-12.

Pena, M.A and Altman, A.H. 2009. Use of satellite derived hyperspectral indices to identify stress symptoms in an Austrocedrus chilensis forest by the aphid Cinara cupressi. International Journal of Pest Management. 55:197206.

Prabhakar, M., Prasad, Y.G and Rao, M.N. 2012. Remote sensing of biotic stress in crop plants and its application for pest management. In: Venkateswarlu, B. et al., (eds) Crop Stress and its Management. Springer Science, Dordrecht. pp. 517-545.

Pratap, B.S., Sharma, O.P and Sant Kumar. 2000. "Economics of Integrated Pest Management: Evidences and Issues", Indian Journal of Agricultural Economics. 55(4): 644-659. 
Riedell, W.E and Blackmer, T.M. 1999. Leaf reflectance spectra of cereal aphid damaged wheat. Crop Science. 39:1835-1840.

Riley, J.R and Reynolds, D.R. 1979. Radarbased studies of the migratory flight of grasshoppers in the middle Niger area of Mali. Proceedings of the Royal Society, London. 204: 67-82.

Riley, J.R. 1989. Remote sensing in entomology. Annual Review of Entomology, 34: 247-257.

Shepherd, R.F., Bennett, D.D., Dale, J.W., Tunnock, S., Dolph, R.E and Their, R.W. 1988. Evidence of synchronized cycles in outbreak patterns of Douglasfir tussock moth, Orgyia pseudotsugata (McDunnough) (Lepidoptera: Lymantriidae). Entomological Society, Canada. 146: 107- 12.

Wolf, W.W., Westbrook, J.K., Raulston, J.R., Pair, S.R and Lingren, P.D. 1995. Radar observations of orientation of noctuids migrating from corn fields in the lower Rio Grande valley, Southwestern Entomologist. 20: 45-61.

Yang, Z., Rao, M.N., Elliott, N.C., Kindler, S.D and Popham, T.W. 2009. Differentiating stress induced by green bugs and Russian wheat aphids in wheat using remote sensing. Computers and Electronics in Agriculture. 67: 64-70.

Yang, Z.M., Rao, N., Elliot, N.C., Kindler, S.D and Elliott, N.C. 2004. Remote sensing to detect plant stress with particular reference to stress caused by green bug: a review. South Western Entomologis. 29: 227-236.

Zhou, Z., Zang, Y., Zhao, Z., Luo, X and Zhou, X. 2010. Canopy hyper spectral reflectance features of rice caused by rice brown planthopper (Nilaparvata lugens) infestation. American Society for Agriculture and Biological Engineering, Pittsburgh, Pennsylvania, June 20 - June 23, 2010.

\section{How to cite this article:}

Sudha Rani, D., M.N. Venkatesh, Ch. Naga Satya Sri and Anand Kumar, K. 2018. Remote Sensing as Pest Forecasting Model in Agriculture. Int.J.Curr.Microbiol.App.Sci. 7(03): 26802689. doi: https://doi.org/10.20546/ijcmas.2018.703.310 